\title{
IMPACTO DE LA PANDEMIA POR COVID-19 EN LA MOTIVACIÓN Y CLIMA LABORAL EN DOS PYMES ROSARINAS
}

\author{
Albano, Sergio \\ Oviedo, Raúl Ricardo \\ Santero, Mariel Sonia \\ Sassone, Mirna \\ Clapera, Facundo \\ Botin, Josefina \\ Secchi, J. Ignacio
}

\section{RESUMEN:}

El presente trabajo detalla los resultados obtenidos de una encuesta implementada en dos pymes de la ciudad de Rosario con el fin de estudiar el impacto de la pandemia por Covid19 en el año 2020. Aquí se analizan los resultados preliminares de dicha encuesta al total de 58 empleados, desglosados adecuadamente para poder evaluar el impacto, tanto positivo como negativo, de la implementación de los protocolos a fin de mitigar la propagación de la enfermedad y poder continuar con las tareas asignadas. Cabe destacar que ambas empresas estuvieron desde el inicio habilitadas a trabajar por pertenecer a un rubro considerado esencial.

PALABRAS CLAVE: Clima Laboral; Covid-19; Motivación; Neurociencias; PyMEs

\section{ABSTRACT:}

This paper details the results obtained from a survey implemented in two SMEs in the city of Rosario in order to study the impact of the pandemic by Covid-19 in the year 2020. The preliminary results of this survey are analysed here for a total of 58 employees, properly disaggregated in order to assess the impact, both positive and negative, of the implementation of the protocols in order to mitigate the spread of the disease and to be able to continue with the assigned tasks. It should be noted that both companies were authorized from the beginning to work because they belong to an area considered essential.

KEYWORDS: Work Climate; Covid-19; Motivation; Neurosciences; SMEs

\section{INTRODUCCIÓN}

El presente informe es un trabajo de investigación que busca estudiar y analizar el impacto que tuvo la enfermedad Covid-19 en las PyMEs de Rosario.

Según la Organización mundial de la salud "La COVID-19 es la enfermedad causada por el nuevo coronavirus conocido como SARS-CoV-2. La OMS tuvo noticia por primera vez de la existencia de este nuevo virus el 31 de diciembre de 2019, al ser informada de un grupo de 
casos de «neumonía vírica» que se habían declarado en Wuhan (República Popular China)" (Organización Mundial de la Salud, 2020).

El 3 de marzo de 2020, se da a conocer el primer caso de Covid-19 en Argentina. Y el 30 de diciembre de 2020 se publicaba en el reporte diario de Argentina que la cantidad de casos de COVID-19 de ese día fueron 11.765, aumentando el total de casos positivos a 1.613.928, de los cuales 144.089 eran casos activos (Ministerio de Salud, 2020).

Para afrontar la pandemia, nuestro país adoptó una serie de medidas sanitarias, económicas y sociales, consensuadas entre el gobierno nacional y todas las provincias junto a la Ciudad de Buenos Aires.

En adición, las pymes tuvieron que readaptar sus lay-outs y formas de trabajo aplicando protocolos sanitarios para evitar la propagación de la enfermedad y los contagios de los trabajadores.

La pandemia cambió en gran parte la forma en que trabajamos, ya sea asistiendo presencialmente o trabajando desde casa. La situación de cambios e incertidumbre genera miedo, estrés y ansiedad en gran cantidad de personas; esto puede provocar agotamiento mental que puede influir tanto en la vida diaria de las personas como en su motivación y rendimiento a la hora de trabajar.

A través de una encuesta, se buscó conocer la opinión de los empleados de dos empresas manufactureras (PyMEs) de la ciudad de Rosario, respecto de la aplicación de los protocolos y el cuidado de su salud, las relaciones con sus compañeros y superiores y cómo se sintieron los empleados al tener que asistir a trabajar. Cabe destacar que, al ser productoras de productos considerados esenciales, las mismas permanecieron abiertas y funcionando durante todo el año, incluyendo el período de cuarentena estricta.

Además, las mismas elaboraron un plan operativo de preparación y respuesta al coronavirus donde todos los empleados contaban con acceso al mismo y podían visualizar los puntos importantes a tener en cuenta, como signos y síntomas, formas de contagio, identificando fases de contención, adecuación, prevención y mitigación de esta enfermedad, como así también los riesgos que traía aparejado cada puesto de trabajo. Se implementaron medidas concretas y se capacitó al personal sobre las mismas.

El gráfico siguiente muestra, a modo ilustrativo, la evolución de la cantidad de ausentes por mes por causas relacionadas al COVID-19 en una de las empresas bajo estudio, desde el comienzo de las restricciones al momento de la medición, según datos proporcionados por la propia empresa. Se contabilizan los sujetos que han tenido por lo menos un día de ausencia en el mes por dichas causas. 


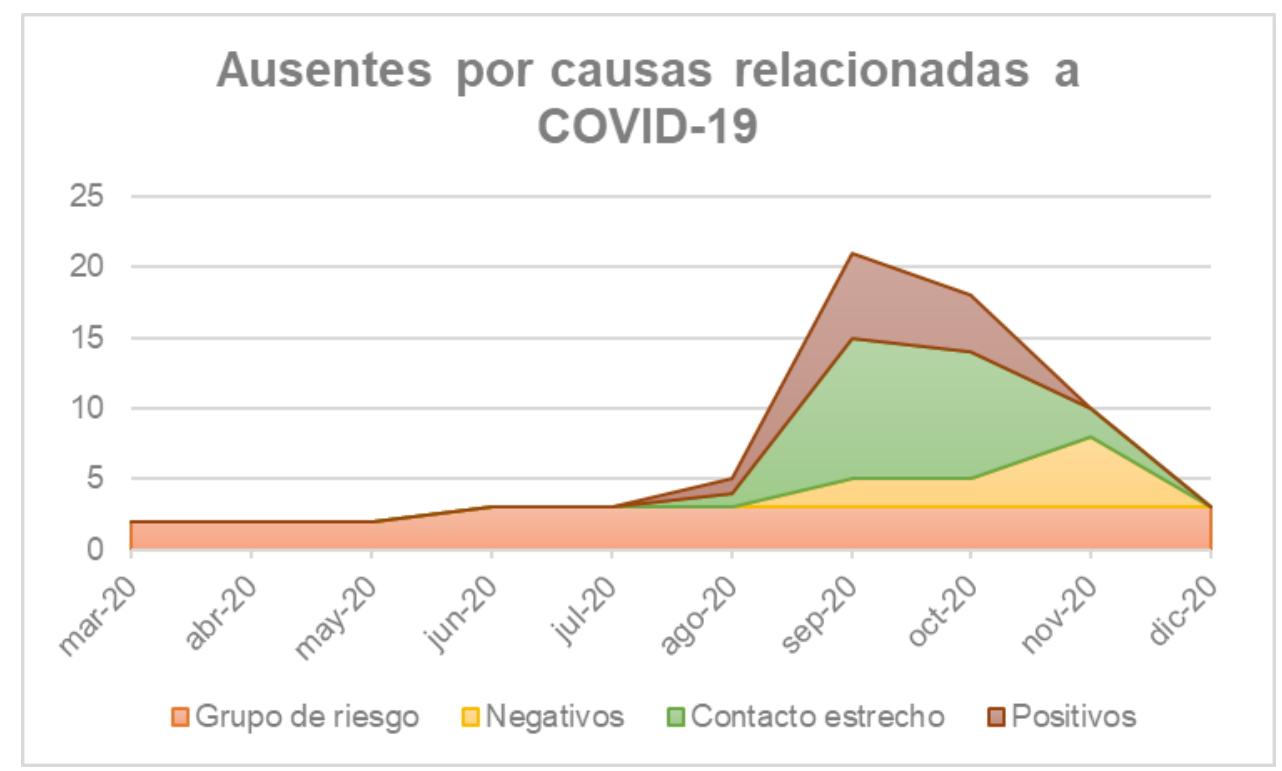

Como se observa, desde el inicio hubo dos casos de sujetos que tomaron licencia por pertenecer a grupos de riesgo, a los que se sumó en el mes de Junio una tercera, por embarazo. Recién en el mes de Agosto aparecieron los primeros dos casos de COVID-19: uno con hisopado positivo y otro por criterio epidemiológico al ser contacto estrecho de un caso positivo. El mes de Septiembre fue el de mayor impacto, con 6 casos de hisopado positivo, 10 casos de contacto estrecho y 2 casos de aislamiento preventivo con hisopado negativo; seguido por 18 casos totales en Octubre. En Noviembre ya no hay casos de hisopado positivo (sí 2 por contacto estrecho y 5 aislamientos preventivos), y en Diciembre solo permanecen los casos pertenecientes a grupos de riesgo.

En cuanto a la extensión de estas ausencias, los casos pertenecientes a grupos de riesgo se mantuvieron ausentes por el resto del año; los casos de hisopado positivo tuvieron un promedio de 16 días fuera de la empresa; los casos de contacto estrecho se ausentaron por un promedio de 12 días; y aquellos que tuvieron un aislamiento preventivo pero su hisopado dio negativo, se ausentaron por un promedio de 5 días.

\section{MARCO TEÓRICO}

\section{CORONAVIRUS}

La enfermedad por coronavirus COVID19 es una enfermedad infecciosa causada por una nueva cepa de coronavirus, que no se había encontrado antes en el ser humano, que se propaga principalmente a través de gotículas de saliva o secreciones nasales. Afecta a las personas de distintas maneras, siendo los síntomas más frecuentes de la enfermedad, fiebre, tos seca y cansancio. Los síntomas más gravosos registrados involucran dificultad para respirar o disnea, dolor u opresión en el pecho e incluso perdida del habla o de movimiento (Organización Mundial de la Salud, 2021). 
En orden de prevenir el contagio y la propagación del coronavirus, la Organización Mundial de la Salud, la Organización Panamericana de la Salud y otras entidades, han publicado ciertas recomendaciones en cuanto a medidas a ser adoptadas. Entre ellas, ciertas recomendaciones a tener en cuenta por las empresas para la protección de los trabajadores y la preparación de los espacios de trabajo (OSHA, 2020), las precauciones que deben tomarse al entrar a casa luego de una jornada laboral e incluso el comportamiento apropiado para el uso del transporte público (OPS/OMS y UNOPS, 2020).

En Argentina, en el transcurso del 2020, el desarrollo de ciertas actividades económicas estuvo regulado con distintas restricciones agrupadas en fases, en función de la evolución de la pandemia. El decreto nacional № 297/20, puesto en vigencia en marzo de ese año, estableció en primera instancia la medida de "aislamiento social, preventivo y obligatorio" que implicaba la abstención de todas las personas de concurrir a sus lugares de trabajo, y en el cual se detallaba las actividades que estaban exceptuadas de tal medida, entre las que mencionaba a las industrias de higiene personal y limpieza (Presidencia de la Nación, 2020). En la provincia de Santa Fe involucraba que las empresas que desarrollasen esta actividad hicieran un pedido de excepción (Gobierno de Santa Fe, 2020), adecuasen sus instalaciones y confeccionasen un protocolo de actuación que respetase los lineamientos incluidos en el Protocolo para Procesos Industriales Específicos que redactó el Ministerio de Producción (Gobierno de Santa Fe, 2020).

Sin dudas, la pandemia y sus derivados han tenido impacto en la economía. A nivel nacional, la Tasa de Empleo - proporción de personas ocupadas con relación a la población total - registró su mínimo en el segundo trimestre de 2020 y para finales del año aún no se había recuperado el nivel del cuarto trimestre de 2019 (Tabla №1).

\begin{tabular}{l|l|l|l|l|l|} 
Tabla N¹ & $4^{\circ}$ T 2019 & $1^{\circ}$ T 2020 & $2^{\circ}$ T 2020 & $3^{\circ}$ T 2020 & $4^{\circ}$ T 2020 \\
\hline Tasa de Empleo & $\mathbf{4 3 , 0 \%}$ & $\mathbf{4 2 , 2} \%$ & $\mathbf{3 3 , 4} \%$ & $\mathbf{3 7 , 4} \%$ & $\mathbf{4 0 , 1 \%}$ \\
\hline Ocupados ausentes & $2,5 \%$ & $10,4 \%$ & $21,1 \%$ & $10,4 \%$ & $6,3 \%$ \\
\hline Ocupados con trabajo desde la vivienda & $5,8 \%$ & $6,1 \%$ & $22,2 \%$ & $21,8 \%$ & $20,2 \%$ \\
\hline $\begin{array}{l}\text { Asalariados que utilizaron sus propias } \\
\text { maquinarias/equipos para realizar su trabajo }\end{array}$ & $2,8 \%$ & $2,6 \%$ & $15,5 \%$ & $16,1 \%$ & $13,6 \%$ \\
\hline
\end{tabular}

Fuente: https://www.indec.gob.ar/

La Tasa de Actividad - que mide la población económicamente activa sobre el total de la población - alcanzó en el cuarto trimestre del año el 45,0\%, aunque se mantuvo 2,2 puntos porcentuales por debajo de igual trimestre de 2019 (Tabla N²). 


\begin{tabular}{|c|c|c|c|c|c|}
\hline $\begin{array}{l}\text { Principales } \\
\text { Cuarto trim }\end{array}$ & $\begin{array}{l}\text { rcado de tra } \\
\text { cuarto trime }\end{array}$ & $\begin{array}{l}\text { o. Total } \\
2020\end{array}$ & omerac & oanos. & \\
\hline \multirow{2}{*}{ Tasas } & \multirow{2}{*}{$\begin{array}{l}\text { Año } 2019 \\
4^{\circ} \mathrm{T}\end{array}$} & \multicolumn{4}{|c|}{ Año 2020} \\
\hline & & $1^{\circ} \mathrm{T}$ & $2^{\circ} \mathrm{T}$ & $3^{\circ} \mathrm{T}$ & $4^{\circ} \mathrm{T}$ \\
\hline Actividad & $47,2 \%$ & $47,1 \%$ & $38,4 \%$ & $42,3 \%$ & $45,0 \%$ \\
\hline Empleo & $43,0 \%$ & $42,2 \%$ & $33,4 \%$ & $37,4 \%$ & $40,1 \%$ \\
\hline Desocupación abierta & $8,9 \%$ & $10,4 \%$ & $13,1 \%$ & $11,7 \%$ & $11,0 \%$ \\
\hline Ocupados demandantes de empleo & $19,0 \%$ & $17,9 \%$ & $11,6 \%$ & $14,8 \%$ & $18,4 \%$ \\
\hline Subocupación & $13,1 \%$ & $11,7 \%$ & $9,6 \%$ & $13,4 \%$ & $15,1 \%$ \\
\hline Subocupación demandante & $9,5 \%$ & $8,2 \%$ & $5,0 \%$ & $8,1 \%$ & $10,3 \%$ \\
\hline Subocupación no demandante & $3,6 \%$ & $3,5 \%$ & $4,6 \%$ & $5,3 \%$ & $4,8 \%$ \\
\hline
\end{tabular}

Fuente: https://www.indec.gob.ar/uploads/informesdeprensa/mercado trabajo eph 4trim20126C4AD 8D8.pdf

A nivel provincial, el Indicador Sintético de Actividad Económica de Santa Fe (ISAE) para el mes de Abril de 2020 registraba su valor mínimo en por lo menos 15 años (IPEC, 2020) y, para el Aglomerado Gran Rosario, en el segundo trimestre de 2020, una Tasa de Desocupación del 17,9\%, 5 puntos porcentuales por encima del trimestre anterior y alcanzando niveles que no se registraban desde el año 2003 (IPEC, 2020).

Dentro de este convulsionado contexto, es natural que quienes continúan desarrollando sus actividades experimenten estrés laboral en mayor o menor grado, siendo los factores más frecuentes relacionados con el trabajo (NCIRD, 2020):

- Preocupación por el riesgo de exposición al virus en el trabajo.

- Atender las necesidades personales y familiares mientras trabaja.

- Manejar los cambios en su carga de trabajo.

- Falta de acceso a las herramientas y equipos necesarios para realizar su trabajo.

- La sensación de no estar contribuyendo lo suficiente en su trabajo o culpa por no ser trabajador en la primera línea de defensa.

- Incertidumbre acerca del futuro en su trabajo y/o empleo.

- Tener que aprender a usar herramientas de comunicación nuevas y superar dificultades técnicas.

- Adaptarse a otro espacio y/u horario laboral.

\section{SATISFACCIÓN LABORAL}

Peiró agrupa las teorías de la satisfacción laboral en el concepto de discrepancia o desajuste, partiendo de la idea de que la satisfacción depende del grado en que coincide lo 
que un individuo busca en su trabajo con lo que realmente consigue de él. La satisfacción será menor cuanto mayor es la distancia entre lo que se quiere conseguir y lo que se obtiene del trabajo (Peiró, 2001).

La satisfacción en el trabajo como una actitud se distingue básicamente de la motivación para trabajar en que esta última se refiere a disposiciones de conducta, es decir, a la clase y selección de conducta, así como a su fuerza e intensidad, mientras que la satisfacción se concentra en los sentimientos afectivos frente al trabajo y a las consecuencias posibles que se derivan de él. En cuanto a esta diferencia planteada, es posible decir que la motivación es el motor, el motivo, el por qué y el para qué de la conducta.

Es importante saber qué es lo que motiva al individuo. Mientras más se pueda conocer acerca de los motivos de un individuo o grupo para trabajar, más se podrá comprender su conducta y saber acerca de cómo mantener su interés, su deseo por trabajar en el mejor nivel que le es posible y en el que sea más útil a la organización.

\section{METODOLOGÍA}

Se realiza un estudio descriptivo, de corte transversal, desde un enfoque cuantitativo.

Se trabajó con un cuestionario autoadministrado, altamente estructurado. El mismo consiste en 15 (quince) afirmaciones a evaluar según el nivel de acuerdo de los encuestados. Estas afirmaciones cubren las cinco dimensiones del clima laboral que guían el proyecto:

- Condiciones de Trabajo.

- Relaciones dentro de la Empresa.

- Formación y Evaluación.

- Comunicación.

- Satisfacción en el Puesto de Trabajo.

La encuesta se realizó a la totalidad de los empleados de ambas empresas durante el mes de Diciembre de 2020, entregándose personalmente los formularios en el lugar de trabajo.

\section{RESULTADOS}

Luego de realizar todos los cuestionarios a los empleados de las distintas empresas, se obtuvieron los siguientes resultados, organizados en torno a las cinco dimensiones que guían el proyecto de investigación desde su inicio. 
CONDICIONES DE TRABAJO

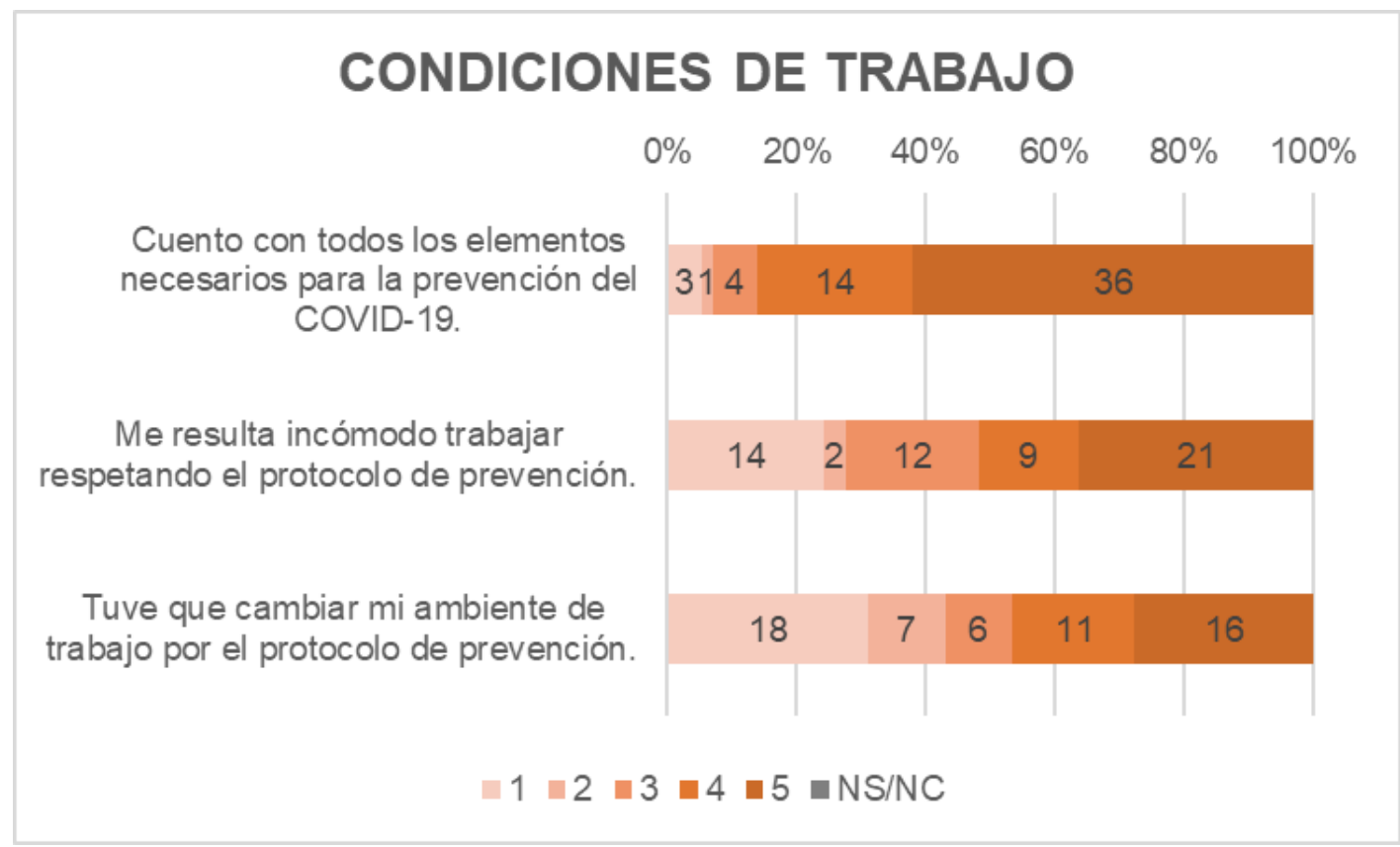

En relación con las condiciones de trabajo, los empleados manifestaron estar en su mayoría de acuerdo en contar con los elementos de protección y prevención del Covid-19. Esto se debe a que ambas empresas tienen inserto un riguroso protocolo y de esta forma la media de esta afirmación alcanza 4,36 puntos de 5.

Se observa también que, en relación con la implementación de este protocolo, 21 personas de las 58 manifestaron estar muy de acuerdo en que estos les resultan incómodos para realizar su tarea diría. Es importante resaltar que, en este punto, los hombres manifestaron estar más de acuerdo que las mujeres y por eso hay una brecha entre sus medias (2,95 en mujeres y 3,61 en hombres).

También, la media de las afirmaciones más baja (3 puntos) fue en la afirmación respecto a sufrir un cambio de ambiente en su trabajo debido al protocolo aplicado. En esta afirmación también resalta que los jóvenes tuvieron menor impacto que los de mayor edad.

\begin{tabular}{|l|r|r|r|r|}
\hline Media de respuestas según edad & $\begin{array}{r}\text { Hasta } 25 \\
\text { años }\end{array}$ & $\begin{array}{r}\text { Entre } 26 \text { y } \\
35 \text { años }\end{array}$ & $\begin{array}{r}\text { Entre } 36 \text { y } \\
45 \text { años }\end{array}$ & $\begin{array}{r}46 \text { años o } \\
\text { más }\end{array}$ \\
\hline $\begin{array}{l}\text { Tuve que cambiar mi ambiente de trabajo por el } \\
\text { protocolo de prevención. }\end{array}$ & 2,86 & 2,82 & 2,84 & 3,89 \\
\hline
\end{tabular}




\section{RELACIONES DENTRO DE LA EMPRESA}

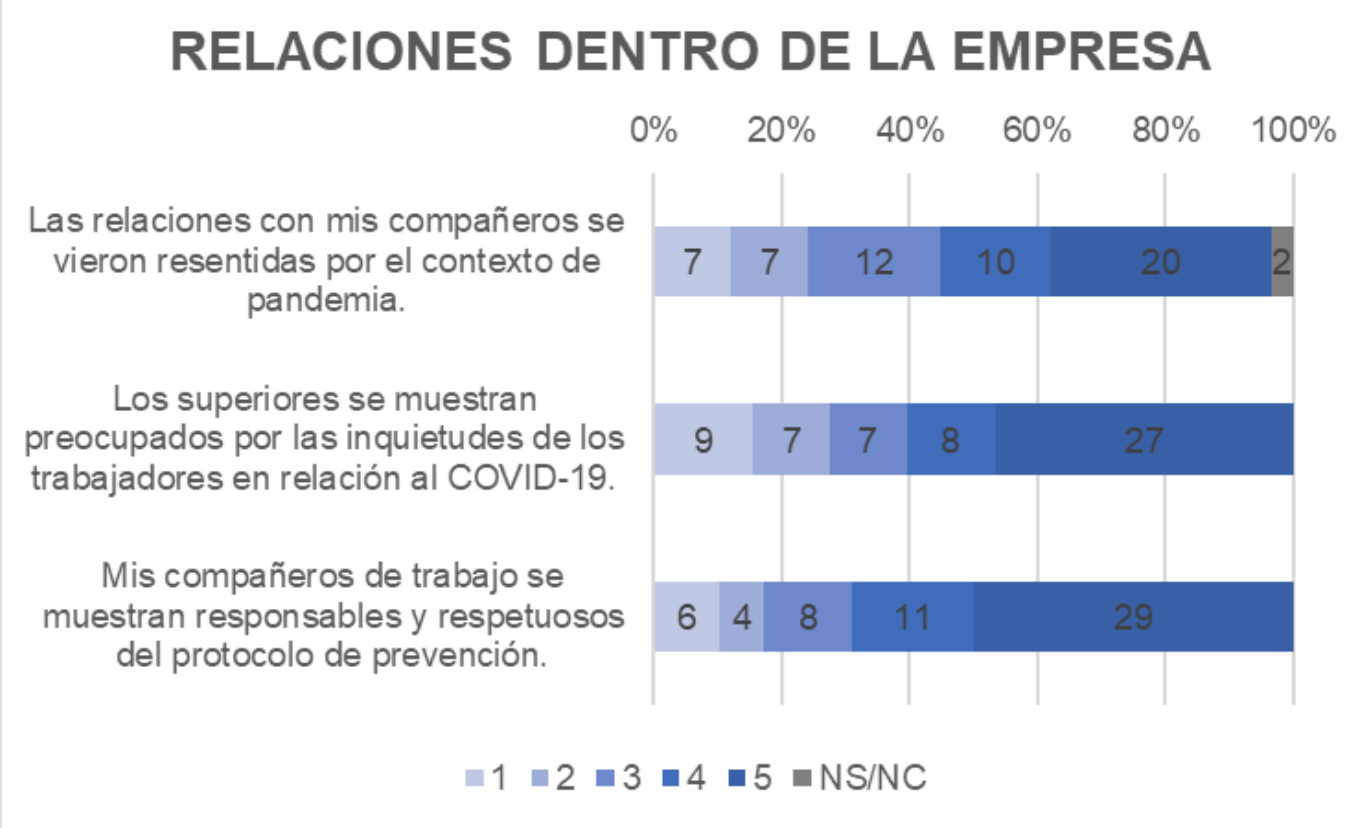

La segunda dimensión está abocada al clima laboral que percibe el individuo en la relación con sus pares y superiores. De esta forma, se puede afirmar que veinte empleados (poco más de un tercio de los encuestados) manifestaron estar muy de acuerdo con el hecho que las relaciones con los compañeros se vieron resentidas.

Hay una particularidad en esta afirmación y es que en la misma se da la mayor brecha de las medias de acuerdo con el nivel de estudios de los colaboradores (1,38 puntos).

\begin{tabular}{|l|r|r|r|}
\hline Media de respuestas según estudios & Primario & Secundario & Superior \\
\hline $\begin{array}{l}\text { Las relaciones con mis compañeros se vieron } \\
\text { resentidas por el contexto de pandemia. }\end{array}$ & 4,05 & 3,28 & 2,67 \\
\hline
\end{tabular}

Por otra parte, se manifestó que los superiores denotan estar involucrados en las cuestiones de salud donde 27 personas estuvieron muy de acuerdo y 8 personas de acuerdo, mientras que 9 personas estuvieron muy en desacuerdo.

Con respecto al cumplimiento del protocolo en la empresa, esta afirmación alcanzó la media más alta en esta dimensión llegando a 3,91 puntos, pese a que no obstante 6 y 4 personas manifestaron estar muy en desacuerdo y en desacuerdo, respectivamente. 


\section{FORMACIÓN Y EVALUACIÓN}

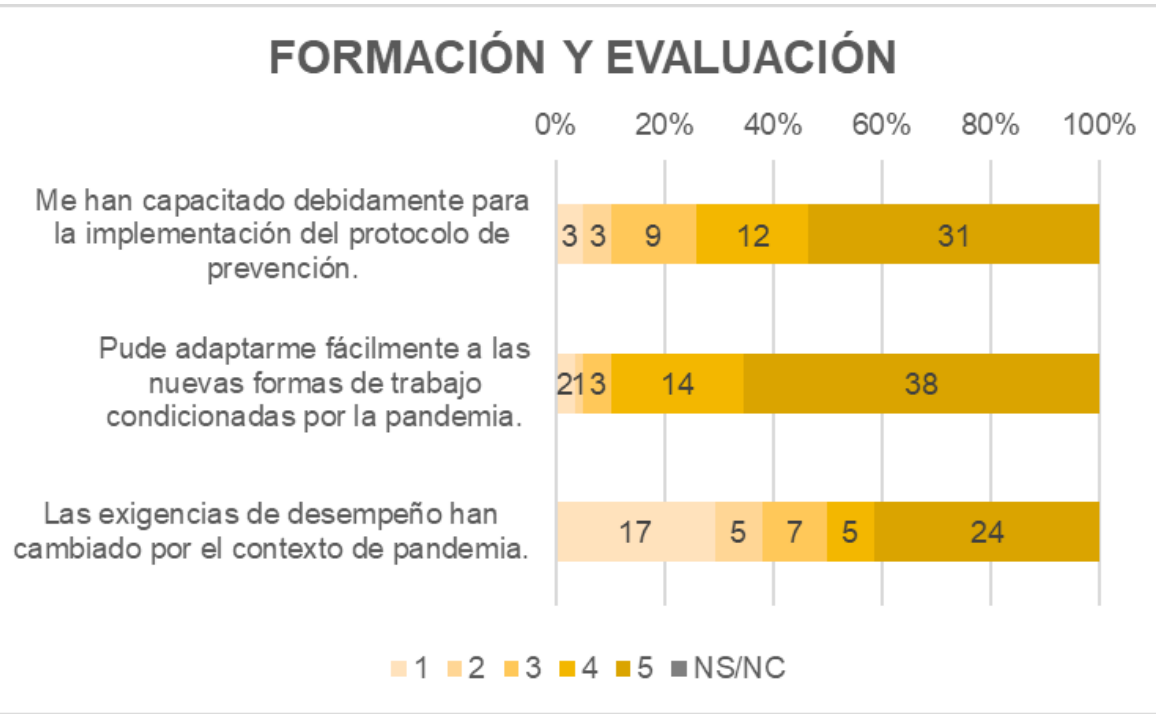

Los empleados de dichas compañías han podido adaptarse a las nuevas modalidades incorporando rápidamente los protocolos implementados mencionados al inicio. 38 trabajadores están muy de acuerdo con este punto y 14 solo de acuerdo. Se alcanzó una de las medias más altas cuando se consultó por esta adaptación siendo de 4,47.

Previo a la adaptación, se capacitó a todo el personal de todas las medidas preventivas tomadas en base a los protocolos aplicados por las empresas encuestadas. Se observó que la mayoría de los empleados incorporaron estas nuevas reglas. No obstante 9 personas indicaron no estar ni de acuerdo ni en desacuerdo.

Analizando el tema de las exigencias que se requirieron a los empleados en el contexto de pandemia se observan respuestas variables y desiguales pese a que la frecuencia de muy de acuerdo estuvo por encima de la de muy en desacuerdo (24 y 17 personas, respectivamente).

\section{COMUNICACIÓN}

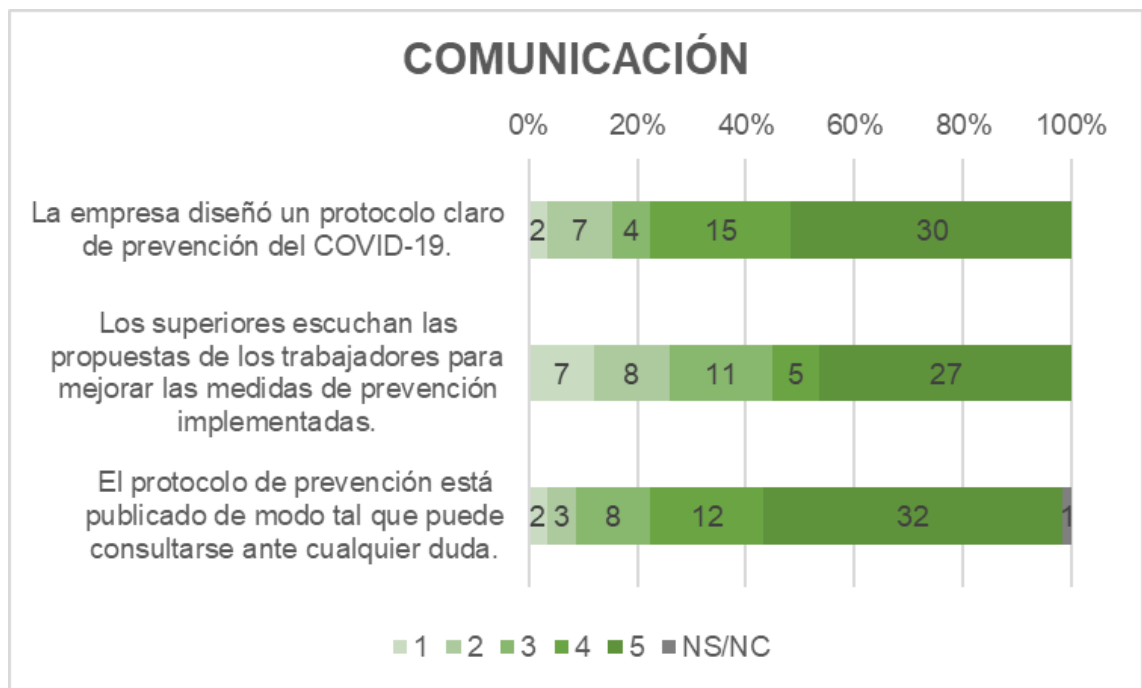


En esta dimensión, se hace referencia exclusivamente al protocolo y su implementación.

Los titulares de las empresas han implementado un protocolo de prevención, no solo a nivel general, sino también en relación con cada puesto en particular. 30 personas afirman estar muy de acuerdo con la claridad del protocolo diseñado, mientras que 32 afirman que está publicado para su consulta.

La media de cada una de las afirmaciones de esta dimensión fue superior en el sexo femenino en todos los casos.

\begin{tabular}{|l|r|r|}
\hline Media de respuestas según sexo & Femenino & Masculino \\
\hline $\begin{array}{l}\text { La empresa diseñó un protocolo claro de } \\
\text { prevención del COVID-19. }\end{array}$ & 4,23 & 4,03 \\
\hline $\begin{array}{l}\text { Los superiores escuchan las propuestas de los } \\
\text { trabajadores para mejorar las medidas de }\end{array}$ & & \\
prevención implementadas. & 3,68 & 3,61 \\
\hline $\begin{array}{l}\text { El protocolo de prevención está publicado de } \\
\text { modo tal que puede consultarse ante cualquier }\end{array}$ & 4,41 & 4,09 \\
\hline
\end{tabular}

También se observa que, a mayor edad de los empleados, la media se incrementa notablemente respecto a la claridad del protocolo diseñado.

\begin{tabular}{|l|r|r|r|r|}
\hline Media de respuestas según edad & $\begin{array}{r}\text { Hasta 25 } \\
\text { años }\end{array}$ & $\begin{array}{r}\text { Entre 26 y } \\
35 \text { años }\end{array}$ & $\begin{array}{r}\text { Entre } 36 \text { y } \\
45 \text { años }\end{array}$ & $\begin{array}{r}46 \text { años o } \\
\text { más }\end{array}$ \\
\hline $\begin{array}{l}\text { La empresa diseñó un protocolo claro de } \\
\text { prevención del COVID-19. }\end{array}$ & 3,57 & 3,82 & 4,32 & 4,44 \\
\hline
\end{tabular}

\section{SATISFACCIÓN EN EL PUESTO DE TRABAJO}

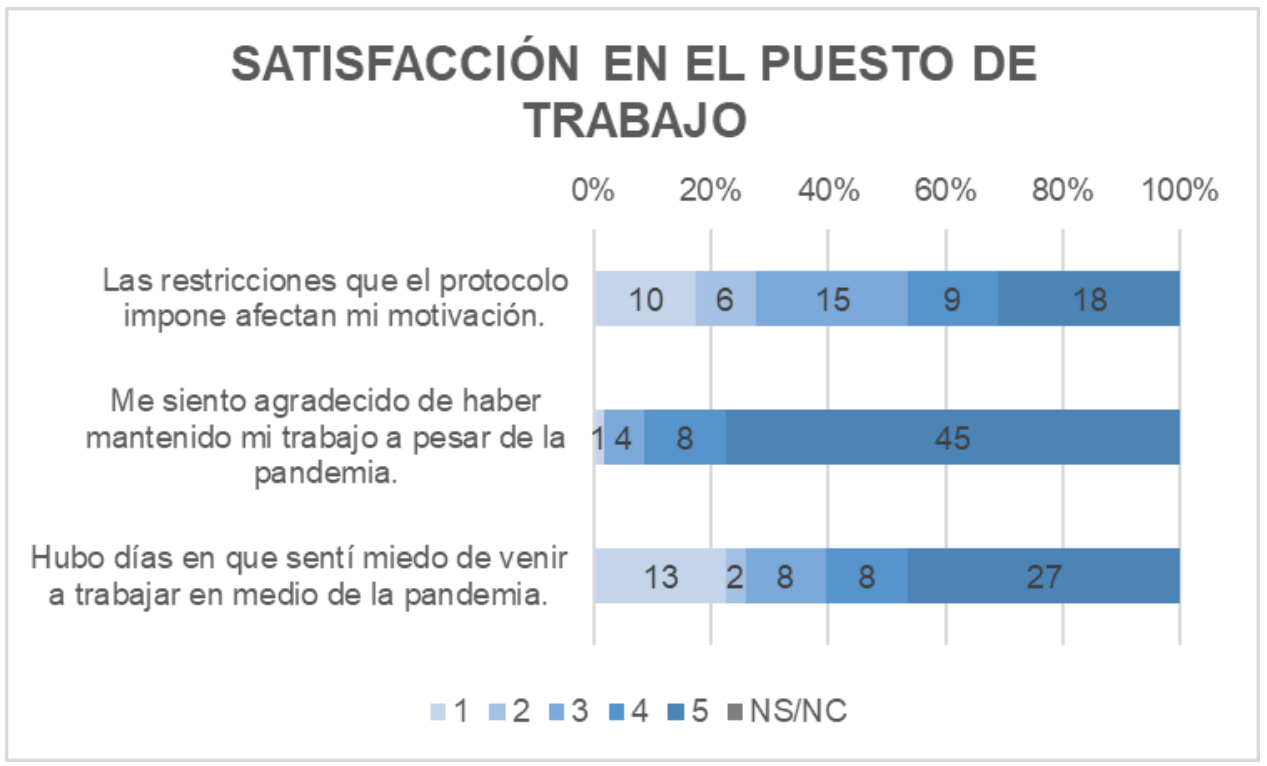

En esta quinta dimensión, referente a la satisfacción de los empleados en su puesto de trabajo en tiempos de pandemia, se observa que 18 personas están totalmente de acuerdo con que las restricciones que el protocolo impone afectan su motivación, mientras que 10 se encuentran totalmente en desacuerdo y 15 no están ni de acuerdo ni en desacuerdo. 
Dentro de esta afirmación se puede ver que los empleados con menor nivel de estudios, tanto nivel primario como secundario, están más de acuerdo con que su motivación se ve afectada por los protocolos siendo la media de 3,86 y 3,23, respectivamente, mientras que la media de los empleados con estudios terciarios/universitarios es de 1,67 , lo que indica que están muy en desacuerdo.

\begin{tabular}{|l|r|r|r|}
\hline Media de respuestas según estudios & Primario & Secundario & Superior \\
\hline $\begin{array}{l}\text { Las restricciones que el protocolo impone } \\
\text { afectan mi motivación. }\end{array}$ & 3,86 & 3,23 & 1,67 \\
\hline
\end{tabular}

Por otro lado, se destaca notablemente la afirmación "Me siento agradecido de haber mantenido mi trabajo a pesar de la pandemia" donde 45 personas de las 58 encuestadas están totalmente de acuerdo con la misma y 8 están muy de acuerdo; solo 1 persona se mostró muy en desacuerdo. La media de esta afirmación es 4,66.

35 empleados estuvieron muy de acuerdo en que sintieron miedo al salir a trabajar durante la pandemia, mientras que 15 estuvieron muy en desacuerdo. En esta afirmación, se puede ver una diferencia entre los empleados con estudios primarios (media 4,00) y los de estudio terciarios/universitarios (media 3,00), donde los primeros se encontraron más de acuerdo con la misma que los de mayor nivel de estudios.

\begin{tabular}{|l|r|r|r|}
\hline Media de respuestas según estudios & Primario & Secundario & Superior \\
\hline $\begin{array}{l}\text { Hubo días en que sentí miedo de venir a trabajar } \\
\text { en medio de la pandemia. }\end{array}$ & 4,00 & 3,37 & 3,00 \\
\hline
\end{tabular}

\section{CONCLUSIONES}

La pandemia del Coronavirus tomó a todos por sorpresa. Nadie se esperó que una enfermedad volviera a azotar a todo el mundo. Si bien comenzó en oriente, el nivel de propagación altísimo hizo que con el pasar del tiempo llegara a la población mundial por completo. Argentina fue un país donde, al comienzo, el impacto no fue tan alto debido al escaso contagio propiciado por las altas restricciones aplicadas. Eso favoreció al comienzo en que todas las empresas que pudiesen seguir trabajando, como las aquí estudiadas, elaboraran sus protocolos y adapten las medidas tomadas por el gobierno en sus tres niveles.

Este informe deja en claro que las empresas objeto de estudio cuentan con un claro y detallado protocolo de prevención que supo instruirse en un principio y que los empleados lo conocen y lo respetan a diario. Se sabe también que lo más importante para prolongar las mejores prácticas de prevención, además de los protocolos y cuidados a tomar, es la responsabilidad social de cada uno de los individuos en cuestión.

Si se miran las empresas analizadas, destaca que la mayoría (casi $80 \%$ ) de los empleados de las mismas estuvo muy de acuerdo con la afirmación que habla sobre estar agradecidos 
de haber mantenido su puesto de trabajo durante la pandemia a pesar de que también más del $50 \%$ de los empleados estuvo muy de acuerdo con la afirmación referente al miedo de ir a trabajar.

Esto demuestra parte de la satisfacción laboral y la importancia de la estabilidad en un empleo y además el miedo inicial fruto del desconocimiento que producía esta enfermedad donde parte de la población, generalmente mayores a 60 años o con determinadas comorbilidades, cuando la contraían corrían riesgo de vida. Por eso, desde el comienzo, si pertenecían a alguno de esos grupos de riesgo el trabajo lo realizaban desde la casa.

\section{REFERENCIAS BIBLIOGRAFICAS}

Gobierno de Santa Fe. (Abril de 2020). Formulario excepción y protocolo higiene COVID-19. Obtenido de Instructivo para empresas industriales:

https://www.santafe.gob.ar/ms/covid19/wpcontent/uploads/sites/36/2020/04/Instructivo-Formulario-Excepci\%C3\%B3nIndustrias.pdf

Gobierno de Santa Fe. (Abril de 2020). Protocolo para procesos industriales específicos... Obtenido de https://www.santafe.gob.ar/ms/covid19/wpcontent/uploads/sites/36/2020/04/Protocolo-para-procesos-industrialesespec\%C3\%ADficos-con-autorizaci\%C3\%B3n-previa-del-Ministerio-de-DesarrolloProductivo.pdf

IPEC. (2020). Indicador Sintético de la Actividad Económica. Santa Fe: Instituto Provincial de Estadísticas y Censos. Obtenido de http://www.estadisticasantafe.gob.ar/wpcontent/uploads/sites/24/2020/07/ISAESF-0420.pdf

IPEC. (2020). Mercado de trabajo. Tasas e indicadores socioeconómicos de los Aglomerados de la provincia de Santa Fe. Santa Fe: Instituto Provincial de Estadísticas y Censos. Obtenido de http://www.estadisticasantafe.gob.ar/wpcontent/uploads/sites/24/2020/07/MerTraSF-1er-trim-2020-nuevo.pdf http://www.estadisticasantafe.gob.ar/wp-content/uploads/sites/24/2020/10/MerTraSF2do-trim-2020.pdf

Ministerio de Salud. (30 de Diciembre de 2020). Informe Diario Vespertino $N^{\circ} 479$. Obtenido de Situación de COVID-19 en Argentina:

Gobierno de Santa Fe. (Abril de 2020). Formulario excepción y protocolo higiene COVID-19. Obtenido de Instructivo para empresas industriales: https://www.santafe.gob.ar/ms/covid19/wpcontent/uploads/sites/36/2020/04/Instructivo-Formulario-Excepci\%C3\%B3n$\underline{\text { Industrias.pdf }}$ 
Gobierno de Santa Fe. (Abril de 2020). Protocolo para procesos industriales específicos.

Obtenido de https://www.santafe.gob.ar/ms/covid19/wp-

content/uploads/sites/36/2020/04/Protocolo-para-procesos-industriales-

espec\%C3\%ADficos-con-autorizaci\%C3\%B3n-previa-del-Ministerio-de-Desarrollo-

Productivo.pdf

IPEC. (2020). Indicador Sintético de la Actividad Económica. Santa Fe: Instituto Provincial de Estadísticas y Censos. Obtenido de http://www.estadisticasantafe.gob.ar/wpcontent/uploads/sites/24/2020/07/ISAESF-0420.pdf

IPEC. (2020). Mercado de trabajo. Tasas e indicadores socioeconómicos de los Aglomerados de la provincia de Santa Fe. Santa Fe: Instituto Provincial de Estadísticas y Censos. Obtenido de http://www.estadisticasantafe.gob.ar/wpcontent/uploads/sites/24/2020/07/MerTraSF-1er-trim-2020-nuevo.pdf http://www.estadisticasantafe.gob.ar/wp-content/uploads/sites/24/2020/10/MerTraSF2do-trim-2020.pdf

Ministerio de Salud. (30 de Diciembre de 2020). Informe Diario Vespertino $N^{\circ} 479$. Obtenido de Situación de COVID-19 en Argentina:

https://www.argentina.gob.ar/coronavirus/informes-diarios/reportes/diciembre2020

NCIRD. (23 de Diciembre de 2020). Centro Nacional de Vacunación y Enfermedades Respiratorias. Empleados: cómo manejar el estrés laboral y aumentar la resiliencia durante la pandemia del COVID-19. Recuperado el Mayo de 2021, de https://espanol.cdc.gov/coronavirus/2019-ncov/community/mental-health-nonhealthcare.html

OPS/OMS y UNOPS. (Abril de 2020). COVID-19: Medidas de prevención para evitar el contagio y la propagación del coronavirus en obras. Obtenido de https://iris.paho.org/bitstream/handle/10665.2/52057/FPLPSCOVID19200007 spa.pd f

Organización Mundial de la Salud. (12 de Octubre de 2020). Información basíca sobre la COVID-19. Obtenido de https://www.who.int/es/news-room/q-a-detail/coronavirusdisease-covid-19

Organización Mundial de la Salud. (2021). Coronavirus. Recuperado el 13 de Mayo de 2021, de https://www.who.int/es/health-topics/coronavirus/coronavirus

OSHA. (2020). Administración de Seguridad y Salud Ocupacional. Guía sobre la Preparación de los Lugares de Trabajo para el virus COVID-19. Estados Unidos: Departamento del Trabajo de los EE. UU. Recuperado el Mayo de 2021, de https://www.osha.gov/sites/default/files/publications/OSHA3992.pdf

Peiró, J. M. (2001). Psicología de la organización (Quinta ed.). Madrid: UNED. 
Presidencia de la Nación. (Marzo de 2020). Aislamiento Social Preventivo y Obligatorio. DNU No 297/20. Buenos Aires, Buenos Aires, Argentina. Recuperado el 13 de Mayo de 2021, de https://www.boletinoficial.gob.ar/detalleAviso/primera/227042/20200320 